This item was submitted to Loughborough's Research Repository by the author.

Items in Figshare are protected by copyright, with all rights reserved, unless otherwise indicated.

\title{
Acoustic emission monitoring of slope instability: development of an active waveguide system
}

\section{PLEASE CITE THE PUBLISHED VERSION}

http://dx.doi.org/10.1680/geng.2003.156.2.83

\section{PUBLISHER}

(C) Thomas Telford Services Ltd

VERSION

VoR (Version of Record)

\section{LICENCE}

CC BY-NC-ND 4.0

\section{REPOSITORY RECORD}

Dixon, Neil, Roger Hill, and John Kavanagh. 2019. "Acoustic Emission Monitoring of Slope Instability: Development of an Active Waveguide System". figshare. https://hdl.handle.net/2134/10235. 
This item was submitted to Loughborough's Institutional Repository (https://dspace.lboro.ac.uk/) by the author and is made available under the following Creative Commons Licence conditions.

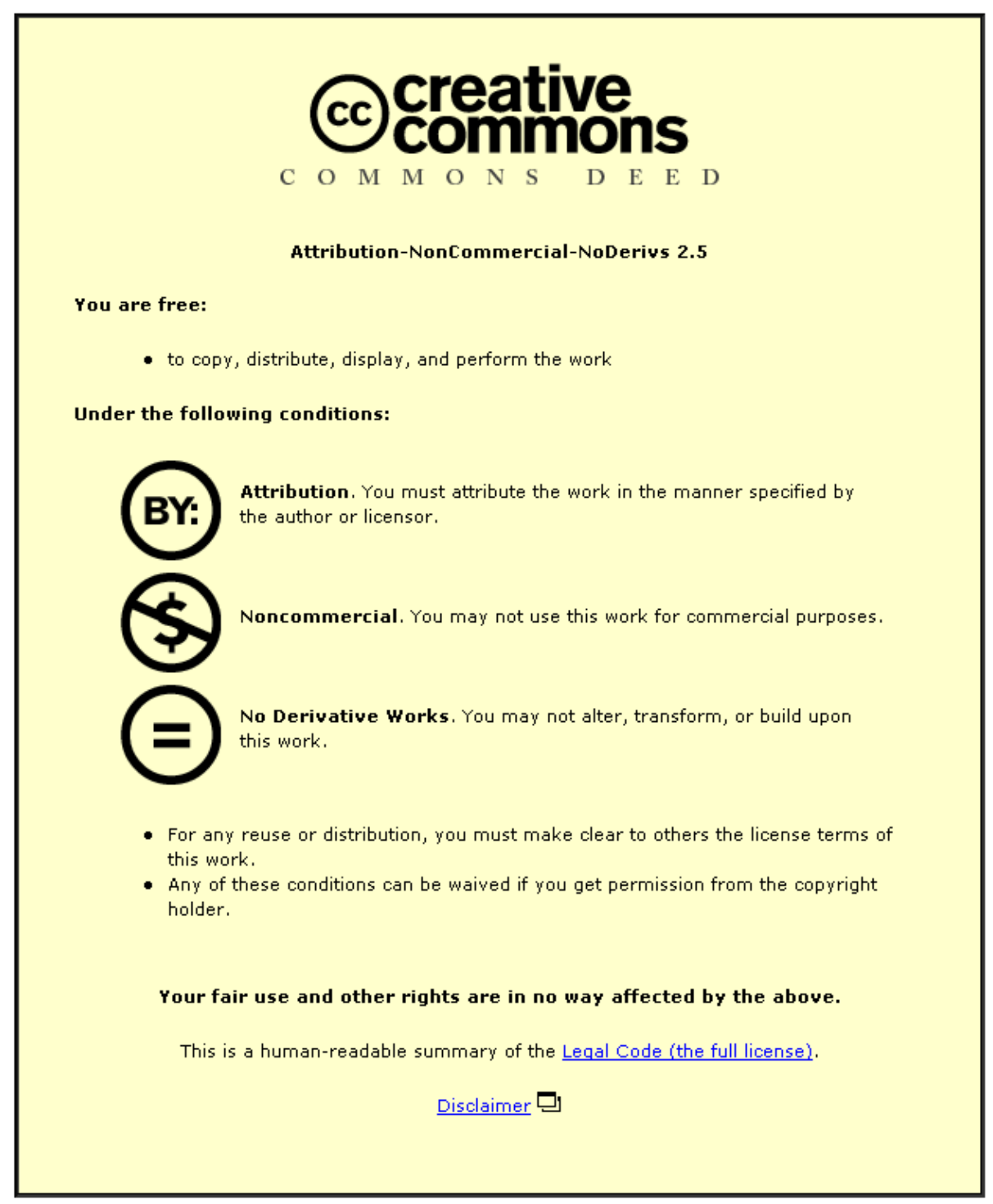

For the full text of this licence, please go to: http://creativecommons.org/licenses/by-nc-nd/2.5/ 
Proceedings of the Institution of Civil Engineers Geotechnical Engineering 156 April 2003 Issue GE2

Pages 83-95

Paper 12549

Received 30/09/2002

Accepted 12/12/2002

Keywords:

field testing \& monitoring

geotechnical engineering

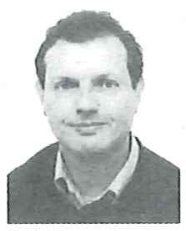

Neil Dixon

Department of Civil and

Building Engineering,

Loughborough University, UK

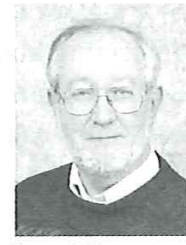

Roger Hill

Department of Chemistry Geotechnical Observations

Trent University, UK
Trent University)

\title{
Acoustic emission monitoring of slope instability: development of an active waveguide system
}

\author{
N. Dixon, R. Hill and J. Kavanagh
}

This paper introduces the concept of using active waveguides as part of an acoustic emission monitoring system for assessing the stability of soil slopes. In soil, acoustic emissions are generated by inter-particle friction, and hence the detection of acoustic emission is an indication of straining. The components of a field monitoring system are introduced, and the factors controlling design and performance of waveguides are discussed. It is proposed that active waveguides (i.e. those that generate acoustic emission when deformed by the host soil) can be used as an efficient method of obtaining signals from depth within a deforming soil body. The results of laboratory tests conducted to validate the active waveguide model are presented. The role played by the soil surrounding the steel tube waveguide is highlighted. Results from two full-scale field trials that involved monitoring unstable slopes provide evidence for the relationship between detected acoustic emission and slope deformation rate. It is shown that active waveguides in conjunction with relevant signal processing methods can be used to provide an early indication of slope instability.

\section{INTRODUCTION}

Many materials undergoing deformation generate acoustic stress waves (also known as acoustic emission (AE) and subaudible noise). Studies of acoustic emission have sought to use the capture and measurement of the signal to determine the extent of the material deformation. Examples of mechanisms that can generate $\mathrm{AE}$ are crack propagation in metals and concrete, and de-bonding between fibres and resins in composite materials. In soil, acoustic emission is generated from inter-particle friction and in rock by fracture propagation and displacement along discontinuities (also referred to as microseismic and rock noise). The presence of $\mathrm{AE}$ is an indication of microscopic defect growth or localised interparticle surface movements within the soil or rock body. Acoustic emission can be detected using suitable sonic or ultrasonic transducers to provide information on the presence and location of straining. Recent advances in the power and portability of instrumentation have led to the possibility of developing systems for use in routine monitoring of unstable geological structures. An example of an appropriate application is providing an early warning of slope instability. In this application the aim is to detect movements as early as possible and to identify changes in the rate of movements.

The acoustic emission technique has the potential to provide an effective slope monitoring system. Its high sensitivity can provide an early warning of instability, and it does not necessarily require measurements to be taken over a prolonged period to establish that deformations are occurring. In addition, it can provide a real-time indication of time-dependent stability (for example related to climatic variations, humanrelated modification and stabilisation works). Acoustic emission monitoring is not a new technique. It has been described in standard texts on geotechnical instrumentation (e.g. Dunnicliff ${ }^{1}$ ) and on landslide investigation (e.g. Schuster and Krizek $^{2}$ ), although to date considerable scepticism exists regarding the practicality of the technique.

Relatively high-energy AE signals are produced by rockfracturing mechanisms, and these signals can travel up to tens of metres through the rock mass. ${ }^{3}$ Sensors placed at the boundary of the rock body (for example at the surface of a slope) are therefore capable of detecting acoustic emission from within the deforming rock mass. Sensor arrays can be used to locate the source of the $\mathrm{AE}$ and hence to provide information on the fracture state of the rock and the mechanism of deformation. ${ }^{4}$ Slopes existing within a large range of geological materials (that is, from competent rock to soft cohesive soils) represent a particular challenge to acoustic emission monitoring. In soils, highly fractured rock and composite geological systems, the combination of the low magnitude of the generated $\mathrm{AE}$ and the high attenuation of the propagating waves (due to the particulate nature of the materials) means that it is not usually possible to monitor material more than a few hundred millimetres from the sensor without providing a low-attenuation acoustic path. Fig. 1 (after Koerner et $a l .{ }^{5}$ ) shows typical variations of attenuation in $\mathrm{dB}$ per metre with frequency for soils and rocks, and includes values in iron and steel for comparison. Traditionally, a metal waveguide has been employed when investigating the generation of acoustic emission in the field in order to transmit signals generated at depth to the sensor located at the surface. However, waveguides have been the subject of little research, and their role in generating and transmitting $\mathrm{AE}$ is poorly understood. This paper primarily considers the 


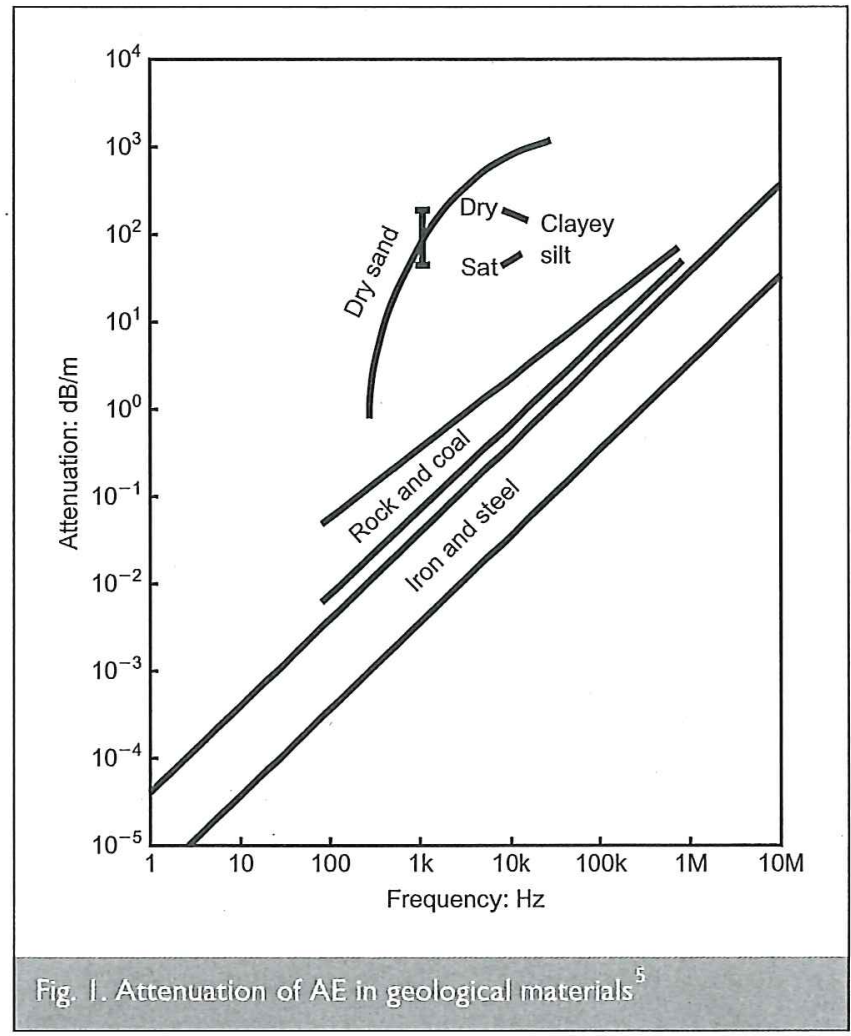

design and performance of this element of the monitoring system.

The most significant contribution in the area of acoustic emission behaviour of soil has been made by Koerner and his co-workers at Drexel University, Philadelphia, who carried out extensive laboratory and field studies of both fundamental AE characteristics of soil and field applications. ${ }^{5,6}$ This work demonstrated that deforming soil produces detectable $\mathrm{AE}$ and that the levels of emissions are directly related to the stress state of the soil. More recently, a number of researchers in Japan have been active in acoustic emission research. ${ }^{7-9}$ Assessment of slope instability has been seen by many researchers as an appropriate application for AE monitoring. ${ }^{10}$ Kotecha, ${ }^{11}$ Rouse et al. ${ }^{12}$ and Dixon et $a l .{ }^{13}$ have reported research conducted in the UK. This body of research has demonstrated that acoustic emission is generated during slope movements and that $\mathrm{AE}$ monitoring is often capable of detecting pre-failure deformations earlier than traditional instrumentation. However, to date, interpretation of acoustic emission data has been qualitative. For example, Koerner et al. ${ }^{5}$ proposed the following classification: (a) Soil masses that do not generate AE are probably not deforming and are therefore stable.

(b) Soil masses that generate moderate levels of $\mathrm{AE}$ are deforming slightly and are considered to be marginally stable.

(c) Soil masses that generate high levels of $\mathrm{AE}$ are deforming substantially and are to be considered unstable.

(d) Soil masses that generate very high levels of AE are undergoing large deformations and can be considered to have failed.

The aim of ongoing research is to develop an acoustic emission monitoring system that produces data to quantify 'moderate', 'high' and 'very high' levels of acoustic emission for a given site. This will enable AE trigger levels to be established and linked to appropriate measures.

The key challenges in developing a robust practical field acoustic emission monitoring system are: difficulties in obtaining AE from deforming soil bodies at depth, owing to very high attenuation rates; concern about contamination of results by background noise; and the qualitative nature of current assessment criteria. The research described in this paper was conducted to address aspects of these key issues through development of an $\mathrm{AE}$ monitoring approach using an active waveguide system. The paper discusses the factors controlling waveguide design including selection of waveguide materials, monitoring strategies and interpretation requirements.

Performance of active waveguides is demonstrated using laboratory experiments and full-scale field trials.

\section{COMPONENTS OF AN ACOUSTIC EMISSION MONITORING SYSTEM}

Components of a typical $\mathrm{AE}$ monitoring system are described below and shown diagrammatically in Fig. 2. An AE sensor provides the means to convert the elastic acoustic emission wave to a variable electrical voltage that can be readily processed, analysed and stored. The transient nature of the $\mathrm{AE}$ 
wave means that geological materials emit a broad range of frequencies, typically from $10 \mathrm{~Hz}$ to $500 \mathrm{kHz}$. Various sensor types are available (including seismometers, geophones, accelerometers, AE transducers and hydrophones), with selection depending upon the site conditions and monitoring strategy. The design of these transducers influences the range of frequencies that can be examined (that is, according to the resonant frequency of the device). For field studies, a compromise has to be made between monitoring low frequencies that have relatively low attenuation, but for which problems can be encountered with contamination from acoustic background noise such as construction activity, vehicles and activities of the general public $(<15 \mathrm{kHz})$, and higher frequencies that are less likely to be contaminated by background noise but for which problems can arise from the high attenuation of the AE signals in soils, with consequent loss of information ( $>100 \mathrm{kHz}$ ). In this study, monitoring has been carried out using a frequency range of $15-45 \mathrm{kHz}$. Sensors are usually attached to the top of a waveguide. Waveguides have traditionally been seen solely as a means of transmitting to the sensor, with minimal loss of energy, signals generated at depth in a soil body. The waveguide is either driven into the ground or installed in a pre-drilled borehole with backfill placed in the annulus between the waveguide and the in-situ soil. Generated acoustic emission propagates along the length of the waveguide and is detected by the sensor. Waveguides are normally made from steel as it is readily available and has a much lower ultrasonic attenuation coefficient than the host materials (Fig. 1). Water-filled plastic tubes have been proposed as waveguides by Shiotani and $\mathrm{Ohtsu}^{9}$ to provide an internal acoustic path, although incorporating water in the waveguide might introduce a potential source of extraneous AE resulting from water movement into or out of the tubing. A pre-amplifier is used to amplify the low-level signals detected by the sensor and transmit them to the main amplifier, which is typically located with the data capture and processing hardware and may be several metres from the sensor and pre-amplifier. Bandpass filters are used to improve the signal-to-noise ratio by removing unwanted low- and high-frequency signals (in this study, frequencies lower than $15 \mathrm{kHz}$ and higher than $45 \mathrm{kHz}$ have been removed). Data capture is via an analogue-to-digital conversion board linked to a PC that is used for data storage and processing.

\section{FACTORS INFLUENCING WAVEGUIDE DESIGN}

\subsection{Transmission of acoustic emission in waveguides}

In selecting the type of waveguide to use, consideration must be given to the transmission of $\mathrm{AF}$ through the guide, including the effect of methods used to join lengths together. Both factors influence attenuation as signals propagate to the sensor. Waveguides are normally formed from steel, owing to the ease of manufacturing the required diameter and thickness and the relative ease of joining sections (that is, either by threaded couplings or by welded joints). Waveguide lengths in the order of tens of metres can be required in order to intersect shear zones in deep-seated landslides, and therefore it is critical to the success of a monitoring system that attenuation in the waveguide is minimised. The main design criteria are: diameter, solid or tube, wall thickness for tubes and method of joining.
Consideration of possible stress waveforms propagating in a waveguide has been used to optimise the waveguide design. Bulk, surface and plate wave modes can exist. Bulk waves (longitudinal and shear) propagate away from a point source in three dimensions and therefore attenuation increases significantly with distance from source. Surface waves (Rayleigh waves, for example) also experience high attenuation due to energy losses related to the contact with adjacent materials. Plate waves propagate in materials with two parallel surfaces and are one-dimensional (Lamb waves, for example). Attenuation is low for this mode. The manner in which Lamb waves propagate is a function of the thickness of the plate and the frequency of the wave. A tube can be assumed to be a curved plate, and thus the relationship between frequency and plate thickness for Lamb wave propagation is also applicable for tubes. Cylindrical Lamb waves (that is, in a tube) also propagate in one dimension with low attenuation. ${ }^{14}$

Steel tube waveguides $50 \mathrm{~mm}$ diameter with $6 \mathrm{~mm}$ wall thickness were selected for the laboratory and field studies. Threaded connectors were used to join lengths. Lamb waves are the dominant mode in a tube with this wall thickness (that is, based on the ratio of wavelength to tube thickness). This results in minimum attenuation of signals transmitted along the length of the waveguide. Studies of threaded connections between lengths of tubing have shown that acceptably low levels of signal loss occur. ${ }^{15}$

\subsection{Selection of backfill material}

Two types of waveguide system can be designed, based on the type of surround to the steel tube waveguide. In the passive waveguide model acoustic emission generates in and propagates through the host soil body to the waveguide and is then transmitted to the sensor. Any detected AE can be used to provide a direct indication of the presence of strains within the soil body and hence can provide an assessment of stability. However, the high attenuation of $\mathrm{AE}$ in soils means that a very small volume of soil can be monitored. Fig. 3 shows results of tests conducted by Shiotani and Ohtsu ${ }^{9}$ to establish the attenuation of different frequency signals in sand. At $30 \mathrm{kHz}$, the signal is attenuated by over $100 \mathrm{~dB}$ (a factor of 100000 ) when it propagates a distance of $100 \mathrm{~mm}$. The low levels of $\mathrm{AE}$ signal generated by deforming soils, particularly fine-grained soils, mean that limited acoustic emission data are likely to be

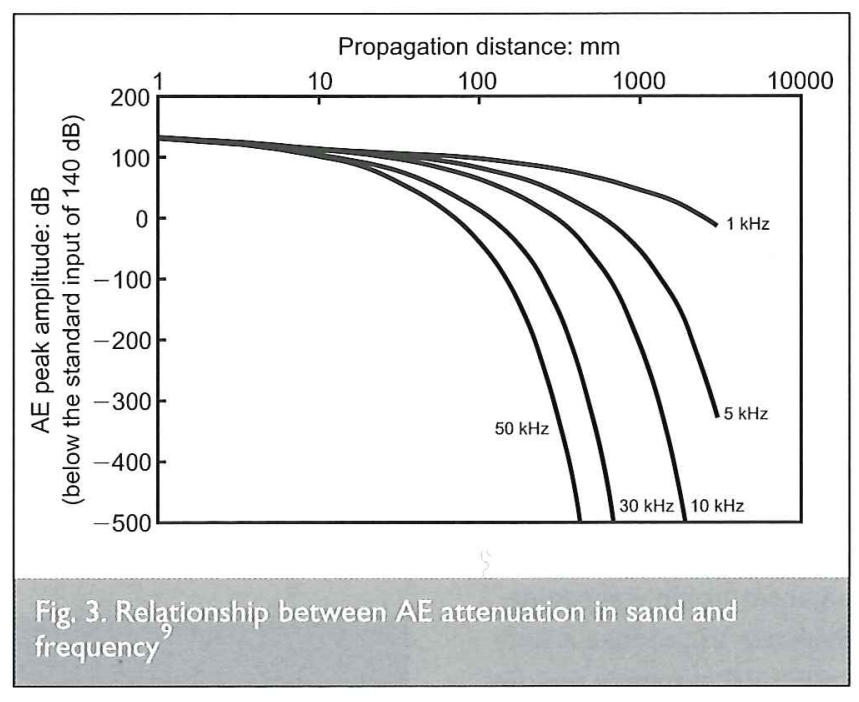


detected from the host soil if frequencies higher than typical background values are used ${ }^{5}$ (that is, $>15 \mathrm{kHz}$ ). The method of installing the waveguide also has to be considered with care. For small slopes it may be possible to drive waveguides to the required depth. However, for larger slopes it will be necessary to install the steel tube in pre-drilled boreholes.

This installation system leads to the major question of what type of material should be selected to backfill the annulus around the central steel element. A passive waveguide must be designed to ensure that installation, including the backfill, does not generate additional sources of $\mathrm{AE}$ during deformation of the host soil. Driven systems are likely to be passive as a result of the waveguide being in direct contact with the in-situ material. For systems located in boreholes, the annulus around the waveguide should be backfilled with low AE activity (that is, quiet) material. However, these materials (such as bentonite grout) have high acoustic attenuation properties, and their use would severely restrict the amount of $\mathrm{AE}$ from the deforming host soil reaching the waveguide and hence being detected by the sensor.

\subsection{Generation of acoustic emission by the waveguide system}

It is proposed that an active waveguide model is more appropriate for use in soil bodies. This design relies upon the waveguide system (that is, including the backfill material) generating $\mathrm{AE}$ in response to being strained by deformation of the host soil body. Acoustic emission can be generated by straining of the steel waveguide element directly (that is, in bending), shearing at the interface between the backfill and steel tube, and compression and shearing in the backfill material. It is considered that minimal amounts of $\mathrm{AE}$ generated within the deforming host soil will propagate to the steel tube as a result of the high attenuation. Transmission path lengths within the backfill to the steel tube are short: hence attenuation is limited, and this results in relatively high-energy signals being transmitted through the steel waveguide to the sensor. If the annulus around the waveguide is backfilled with 'noisy' material, it is possible to obtain effective acoustic emission data in response to deformation of 'quieter' fine-grained host soils. As the host material deforms, the column of high $\mathrm{AE}$ response backfill material will be deformed, leading to the production of detectable acoustic emission. To get the maximum amount of information the waveguide system should be calibrated so that recorded acoustic emission behaviour is related to the mode, magnitude and rate of the ground deformations in the host soil adjacent to the waveguide. Research to produce a fully calibrated system is ongoing.
Coarse-grained soils (such as sand and gravel) can be used as 'noisy' backfill, as they can produce relatively large-amplitude $\mathrm{AE}$ signals when deformed. They are also in ready supply, easy to place, and cheap. In the remainder of the paper the term 'waveguide' is used to denote the combined system of steel tube and surrounding backfill material. Performance of an active waveguide system has been investigated via a series of simple laboratory experiments and by carrying out full-scale field trials. Details of methodology, typical results and a discussion are presented below.

\subsection{Waveguide location}

In common with traditional subsurface deformationmonitoring techniques it is desirable for the waveguide to be installed to a depth sufficient to ensure that it penetrates any existing shear surfaces, or any that may form during the onset of failure. A main shear zone would be expected to produce maximum strains within the waveguide system. Hill et al. ${ }^{16}$ have demonstrated that it is possible to locate the position of $\mathrm{AE}$ activity along the length of a waveguide by analysis of the acoustic emission waveforms. This information can be used to exclude extraneous acoustic emission (such as that generated by sources at or near the surface) and to obtain information on depth of shear zones and hence mode of slope deformation. Waveguides that do not penetrate the main shear surface can still potentially provide useful information. Many failure surfaces are non-circular, and in these cases internal shear strains occur within the slide mass. Guides positioned both through and above the main shear surface are capable of detecting $\mathrm{AE}$ from these modes of deformation.

\section{DATA PROCESSING AND MONITORING PHILOSOPHY}

Acoustic emission waveforms can be described and quantified using a range of parameters. Fig. 4 shows an $\mathrm{AE}$ waveform obtained from deforming soil, with its associated upper bound envelope, and defines parameters that can be used to characterise the signal. The traditional acoustic emission

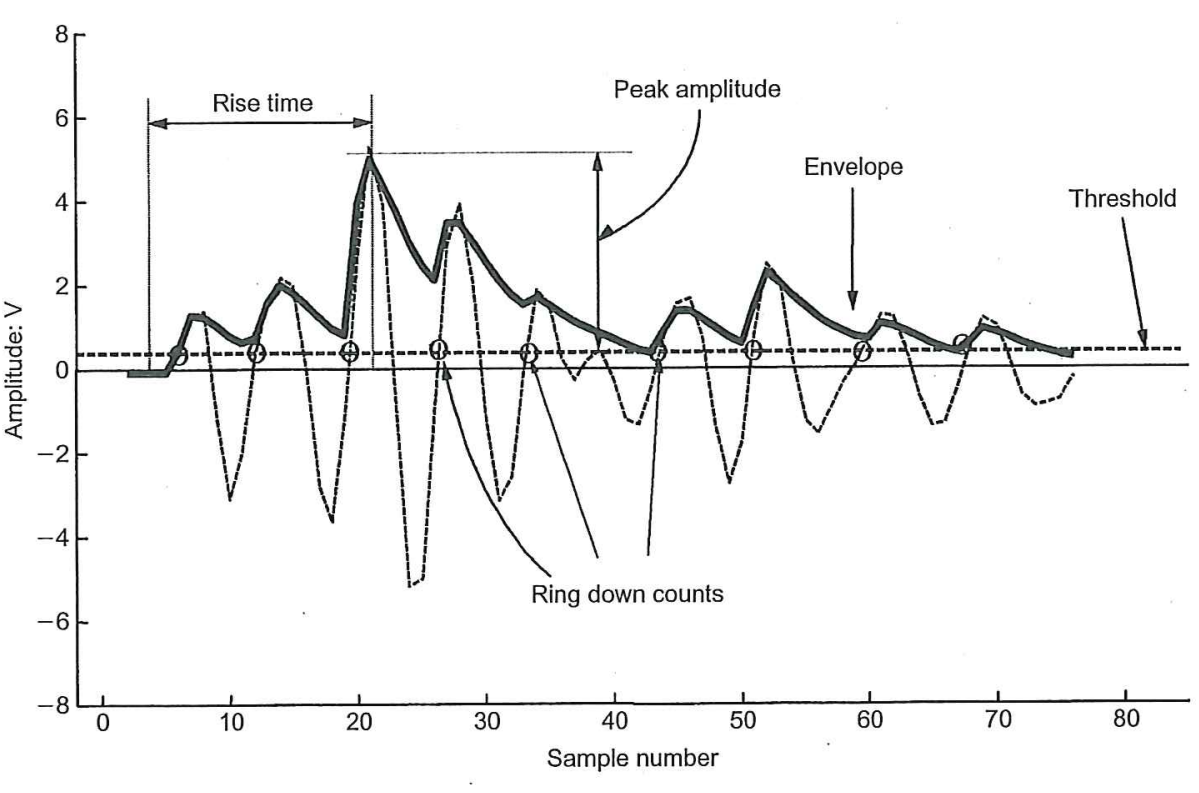

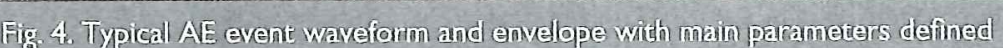


parameters used are the ring down count (RDC) and event amplitude values. An RDC is simply a count of signal threshold crossings, with the threshold value predetermined to eliminate background and/or electronic noise. Event amplitude is the peak voltage recorded for a given event. Fig. 4 shows nine counts and one AE event. Count and event rates are also frequently used. Peak amplitude and the area under the event envelope are related to the energy of an event.

As a direct result of recent improvements in computer power and portability, it is now possible to employ digital data capture of the AE waveform and real-time processing techniques on site. However, the use of a monitoring frequency range of $15-45 \mathrm{kHz}$ as in this study results in unmanageably large data files. In this study the event envelope has been used rather than the full waveform in order to keep data files manageable. The analogue values that define the envelope are converted to digital values and saved to disk for processing. As shown in Fig. 4 most of the AE parameters defining the full waveform are also obtained from the event wave envelope. This can be done in real time or during post-processing.

Most of the field monitoring trials carried out as part of previous studies have used measurements of counts or events, and this has led to the qualitative system of assessment suggested by Koerner et al. ${ }^{5}$ This method of assessment needs to be used with care, because not only do different soils generate widely varying levels of detectable $\mathrm{AE}$ for the same strain and stress states, ${ }^{5}$ but problems may also be encountered in quantifying the influence of the measuring system on the number of counts/events detected. In order to introduce more rigour into the assessment of field acoustic emission data the authors have employed a combination of the above techniques with simple statistical analysis. Calculations of arithmetic mean, standard deviation and root mean square of the signal level have been carried out using both the entire data set from a given monitoring period and also only the parts of acoustic emission signal above a defined threshold level.

Problem slopes should ideally be monitored continuously for signs of instability. The monitoring system must be capable of real-time assessment of large amounts of data if such a system is to provide an early warning. In addition, the significance of the $\mathrm{AE}$ data must be understood and hence trigger values set, such that given levels of acoustic emission activity result in predetermined actions being carried out. The cost of the prototype AE instrumentation used in this study meant that it was not practical to provide a system for continuous monitoring. Consequently there is the possibility that the most active periods of deformation may have been missed, although during the approach of slope instability there is evidence that the process of stress redistribution during progressive failure results in ground deformations occurring over an extended period of time (e.g. Cooper et al. ${ }^{17}$ ). Slopes would be expected to generate AE over the same extended period, thus making monitoring at discrete times a viable approach. The field trials described below were designed in part to investigate this hypothesis.

\section{LABORATORY STUDIES OF ACTIVE WAVEGUIDE SYSTEMS}

The AE system used in this study comprised a piezoelectric transducer with a resonant frequency of $30 \mathrm{kHz}$ in conjunction with bandpass filters used to remove frequencies below $15 \mathrm{kHz}$ and above $45 \mathrm{kHz}$. These frequencies were selected as a compromise to minimise lower-frequency background noise while still having relatively low attenuation. The filters also ensured that only data from the range of frequencies over which the sensor is most sensitive were utilised. A preamplifier and a main amplifier were used to boost the signal by a total of $96 \mathrm{~dB}$ prior to processing. The same system was used for the field studies.

A simple laboratory experiment was designed to validate the active waveguide model. The experiments also made it possible to assess the performance of two backfill materials (sand and gravel), and this information was used in designing the field trials. Fig. 5 shows schematic plan and cross-section diagrams of the apparatus used. A length of steel tube $50 \mathrm{~mm}$ diameter and $6 \mathrm{~mm}$ thick (as used in the field installations) was located in a soil-filled rigid plastic box. An axle was located at the lower end of the tubing so that it could be rotated about this point. The box was filled with either uniformly graded fine sand or uniformly graded sub-rounded medium gravel, both of which were used as backfills in the field trials. A horizontal load was applied to the top of the tube using weights acting over a pulley. Load was applied in increments, and horizontal displacement of the top of the tubing monitored. The transducer was attached to the top of the tubing. The data capture routine employed resulted in acoustic emission being recorded throughout the test period but for a total of only $20 \%$ of the time. Capture of continuous acoustic emission data was not possible owing to limitations of computer disk storage.

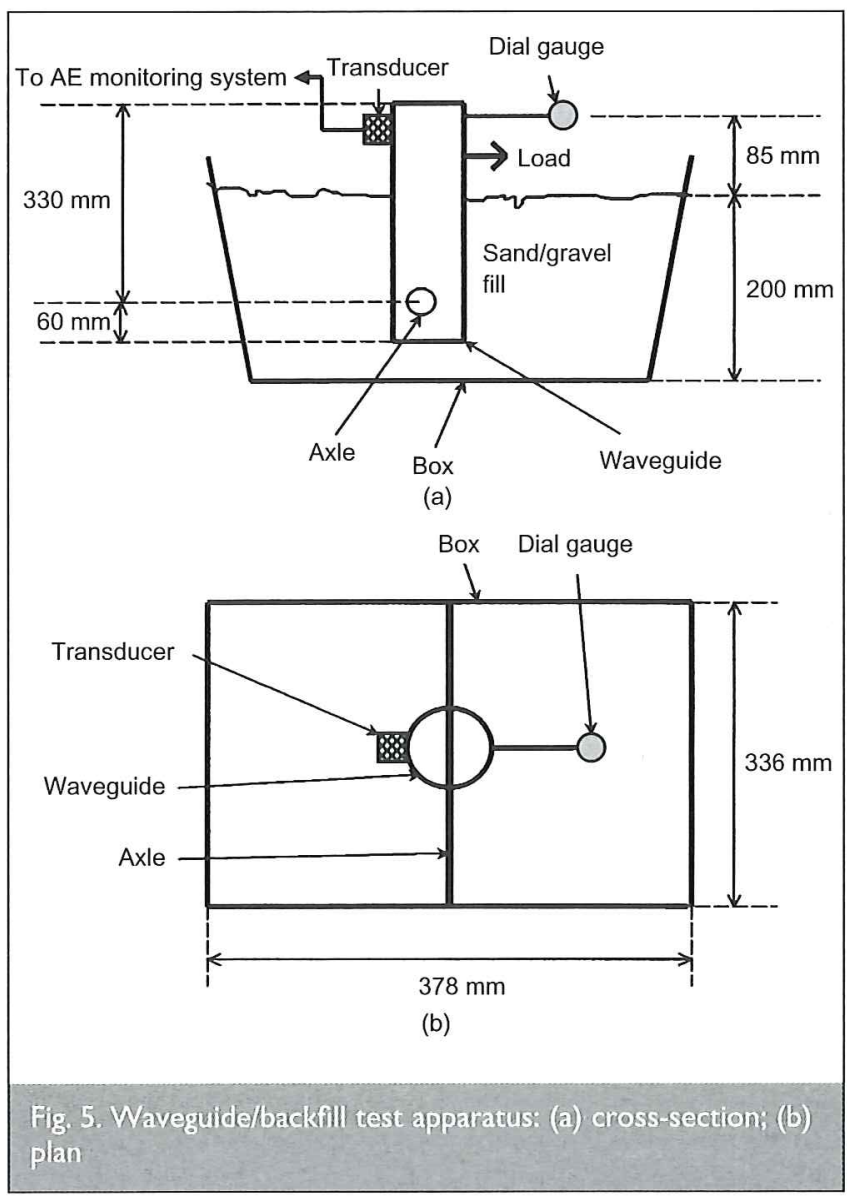


Figure 6 is a plot of cumulative post-threshold acoustic emission data points against time for a two-stage load test conducted using sand. Also shown is the waveguide displacement. After the initial load had been placed, acoustic emission and waveguide displacements were monitored for a period of $15 \mathrm{~min}$. The load was then held constant for $1 \mathrm{~h}$ before the second load increment was added. There is a clear correlation between cumulative $\mathrm{AE}$ and recorded movement. The result of a one-stage load test conducted using the gravel is shown in Fig. 7, and this also demonstrates a consistent relationship between cumulative $\mathrm{AE}$ and displacement. Fig. 8 shows the evolution of $\mathrm{AE}$ event peak amplitude and demonstrates a correlation between the magnitude of
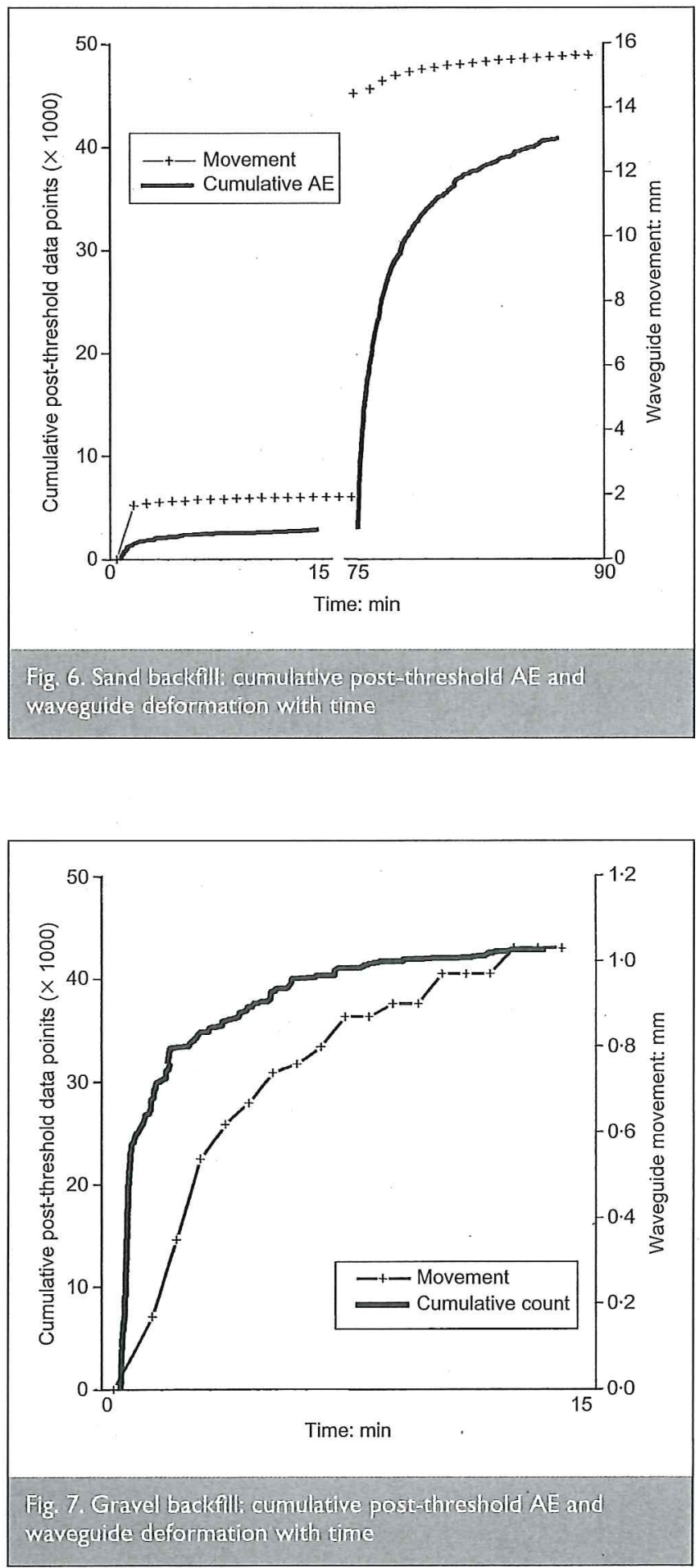

individual $\mathrm{AE}$ events and strain rate: that is, the largeramplitude events occur in the initial part of the test when strain rates are highest. In general, the gravel produced larger events than the sand (Fig. 8). An interesting feature of the gravel test is that there were periods towards the end of monitoring when there were no displacements and no recorded AE. This 'slip stick' behaviour was not observed in the sand. Also of note is that for the same magnitude of deformation the sand and gravel tests generate very different numbers of postthreshold $\mathrm{AE}$ data points: for example, for $1 \mathrm{~mm}$ of displacement the sand generated 5000 data points and the gravel 40000 .

These results confirm that, in an active waveguide system, the important mode of acoustic emission generation is one of local straining of the soil surround and interaction between the steel tube and soil. In the field, deformation of the system will be caused by displacements of the host soil, with the waveguide acting as an 'acoustically active strain gauge' that responds to deformation within the slope. Acoustic emission will be greatest immediately after initial host soil deformation, gradually reducing in activity, mirroring the returning equilibrium of the host soil/waveguide system. The larger particles in a gravel soil require a greater input of energy to make them slip relative to one another. Therefore larger acoustic emission events will be generated, but there will also be periods without any AE when the destabilising forces are increasing towards the threshold required to cause further particle slippage. This is the 'slip stick' behaviour observed in the gravel test (Fig. 7). Destabilising forces required to displace sand particles are smaller, owing to the smaller particle size. Prolonged periods of particle slippage occurred in the sand backfill, denoting continuous generation of acoustic emission following an episode of host soil deformation: that is, there is no observable 'slip stick' behaviour.

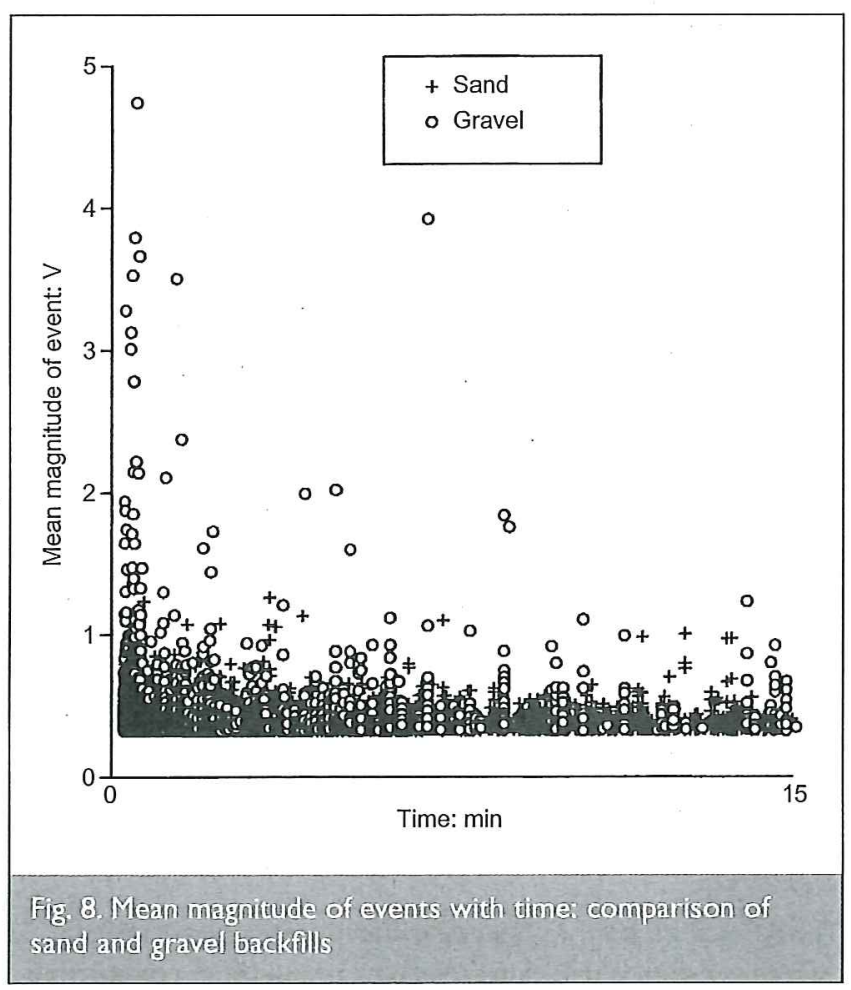




\section{FIELD TRIALS OF AN ACTIVE WAVEGUIDE SYSTEM}

Evaluation of any new monitoring technique must include an assessment of its performance for a range of site conditions, and a direct comparison must be made with the established methods that it is intended to complement. In this instance, a comparison has been made between acoustic emission and inclinometer measurements. The objectives of the field study were:

(a) to assess the performance of waveguides with different backfills in slopes experiencing different rates and magnitudes of strains

(b) to compare the $\mathrm{AE}$ response to the magnitude and rate of deformations measured using a standard inclinometer system

(c) to assess the suitability of the technique for routine slope monitoring.

Two field trials were conducted. Waveguide installation, monitoring strategy and the measured $\mathrm{AE}$ and deformation behaviour are considered below.

\section{I. Description of trial sites and instrumentation programmes}

The first trial entailed instrumentation of a coastal slope at Cowden, located on the north- eastern coast of England. The cliffs at this location are $20 \mathrm{~m}$ high and are formed of stiff, fine-grained glacial till. Failure of these slopes takes the form of rotational sliding, which is triggered by marine erosion of the toe. This site was chosen for the following reasons:

(a) Consistently high erosion rates meant that a slope failure was expected to occur shortly after installation of the instrumentation.

(b) The Building Research Establishment's coastal cliff test section was situated $100 \mathrm{~m}$ from the trial site. A slope failure at this location was studied in detail during the early 1980 s. ${ }^{18}$ This provided information on the failure mechanism of the cliffs, and on the engineering properties of the soil.

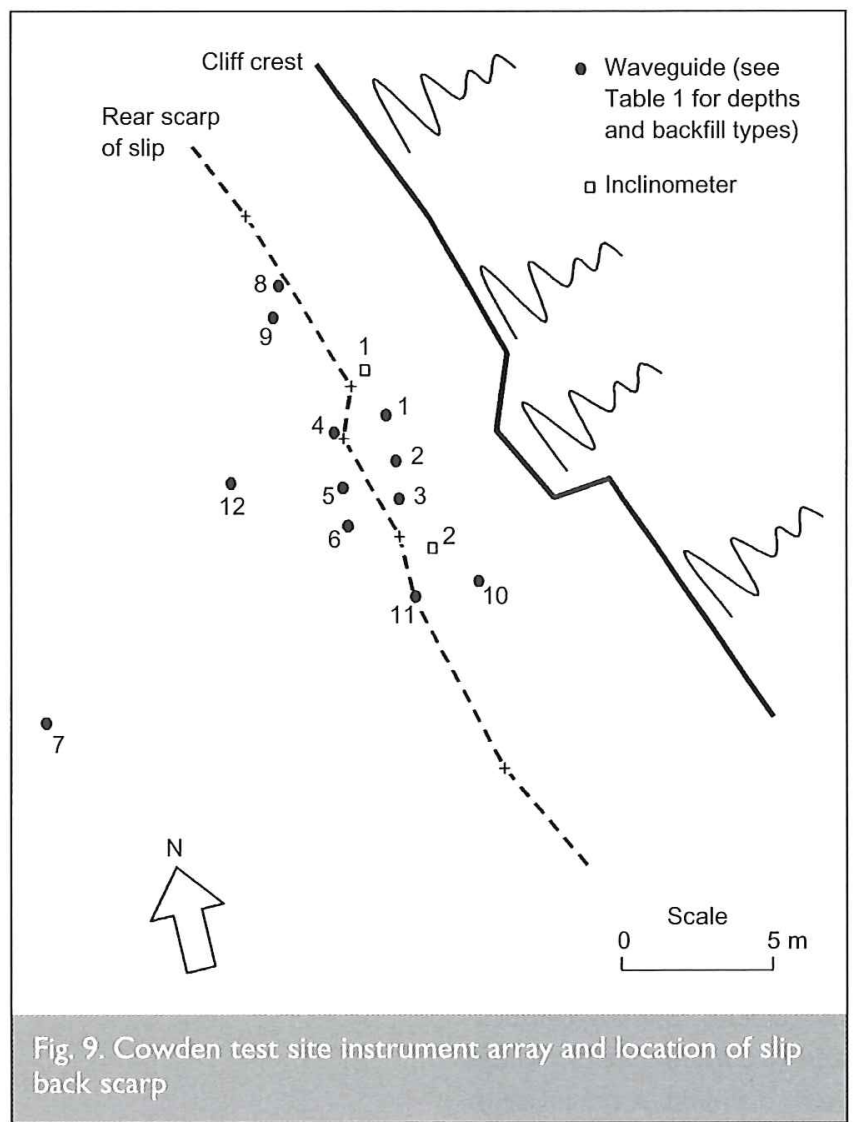

intersect potential basal shear surfaces identified by Butcher. ${ }^{18}$ The rest were installed to depths of either 6 or $12 \mathrm{~m}$. Each waveguide was installed in a $150 \mathrm{~mm}$ diameter borehole, with the annulus between the waveguide and in-situ soil backfilled with bentonite grout, fine sand or medium gravel. The bentonite was expected to provide low levels of $\mathrm{AE}$ when deformed (passive waveguide). Both the sand and gravel were expected to produce relatively high AE (active waveguide). The depth of each waveguide and the type of backfill used are given in Table 1. The boreholes were formed using the

The cliff was instrumented prior to an active winter season, when winter storms could be expected to produce increased marine erosion and hence instability.

A total of twelve $50 \mathrm{~mm}$ diameter steel tube waveguides were installed at the locations shown in Fig. 9. The lengths of waveguide required to ensure penetration of all potential shear zones dictated that driven systems could not be used. Some of the waveguides penetrated to a depth of $21 \mathrm{~m}$ below the slope crest in order to

\begin{tabular}{|llcl|}
\hline Instrument type & Code & $\begin{array}{c}\text { Depth below ground } \\
\text { level: } \mathrm{m}\end{array}$ & Backfill \\
\hline Waveguide & WGI & $21 \cdot 0$ & Sand \\
Waveguide & WG2 & $21 \cdot 0$ & Gravel \\
Waveguide & WG3 & $21 \cdot 0$ & Grout \\
Waveguide & WG4 & $12 \cdot 0$ & Grout \\
Waveguide & WG5 & $12 \cdot 0$ & Sand \\
Waveguide & WG6 & $12 \cdot 0$ & Gravel \\
Waveguide & WG7 & 18.0 & Sand \\
Waveguide & WG8 & $12 \cdot 0$ & Sand \\
Waveguide & WG9 & 6.0 & Sand \\
Waveguide & WGI0 & $12 \cdot 0$ & Sand \\
Waveguide & WGII & 6.0 & Sand \\
Waveguide & WGI2 & 6.0 & Sand \\
Inclinometer & II & $21 \cdot 0$ & Grout \\
Inclinometer & I2 & $21 \cdot 0$ & Grout \\
& & & \\
\hline
\end{tabular}


continuous flight augering technique and remained stable. This method is ideal for installing instruments in stable fine-grained deposits, as the formation of a constant-diameter annulus of backfill material is preferable. Groups of waveguides with different backfill materials were positioned along the cliff edge and also back from the slope crest. Waveguides 7 and 12 were located back from the slope as controls used to assess the levels of environmental noise and the sensitivity of the $\mathrm{AE}$ instrumentation. Two inclinometer casings were installed to depths of $21 \mathrm{~m}$ (Fig. 9). Although a large number of instruments were installed at Cowden it is unlikely that they would have had a significant influence on the stability of such a large slope ${ }^{17}$ (that is, acting as reinforcement).

The second field trial was carried out in a brick pit formed in Gault Clay, a heavily overconsolidated deposit, at Arlesey in Bedfordshire, England. A slope $4.5 \mathrm{~m}$ high formed entirely of Gault Clay was instrumented with waveguides and inclinometer casings, and destabilised in a controlled manner by excavating successively larger slices from the toe. The aim was to produce deformations in the area behind the slope as a result of stress relief. Deformation and $\mathrm{AE}$ monitoring were carried out during the period of excavation in order to assess the ability of the techniques to detect pre-failure ground movements. Six waveguides and two inclinometer casings were installed at the locations shown in Fig. 10 using the same techniques as employed at Cowden. One waveguide (WG4) was installed by driving a $50 \mathrm{~mm}$ diameter solid steel rod to a depth of $2 \cdot 7 \mathrm{~m}$. The depth of each waveguide and the type of backfill used are given in Table 2 . The waveguides may have had a reinforcing effect on the Arlesey slope owing to its small size, but this is not considered an important factor as the mode of slope failure was not investigated in this instance: the aim was to generate slope deformations resulting from stress relief. Monitoring was carried out on 25 separate days in total. The site was monitored on 10 occasions prior to the first cut. Excavation of cuts 2-5 took place 1, 2, 3 and 7 days respectively after cut 1 . Cut 6 was made 55 days after cut 1 . Fig. 10 shows the position of the cuts. The large number of measurements taken prior to the first cut was important as they established the background $\mathrm{AE}$ levels during equilibrium conditions.
6.2. Cowden results: relatively rapid slope movements The first few sets of inclinometer readings indicated that prefailure slope movements were occurring. Although acoustic emission monitoring was being carried out during this period, the quality of the data and the number of readings taken were inadequate for assessing whether the acoustic emission monitoring had detected these initial pre-failure deformations. However, monitoring of the ground deformations and acoustic emission was continued through a winter period. Each reading from a waveguide took the form of sampling the AE signal envelope during a $3 \mathrm{~min}$ period. Major slope movements finally occurred in the following April, making the inclinometer casings unusable. Figs 9 and 11 show the position of the landslide rear scarp, which passed through the middle of the instrument array. Some waveguides penetrated the slide block and a number of others were close to, but behind, the main shear surface.

To facilitate comparison with acoustic emission data, the deformations recorded by inclinometers 1 and 2 are presented in Fig. 12 as displacement rates plotted against the number of days from commencement of monitoring. The values are plotted at the end of the period to which they refer. The two inclinometers produced similar rates of displacement, including

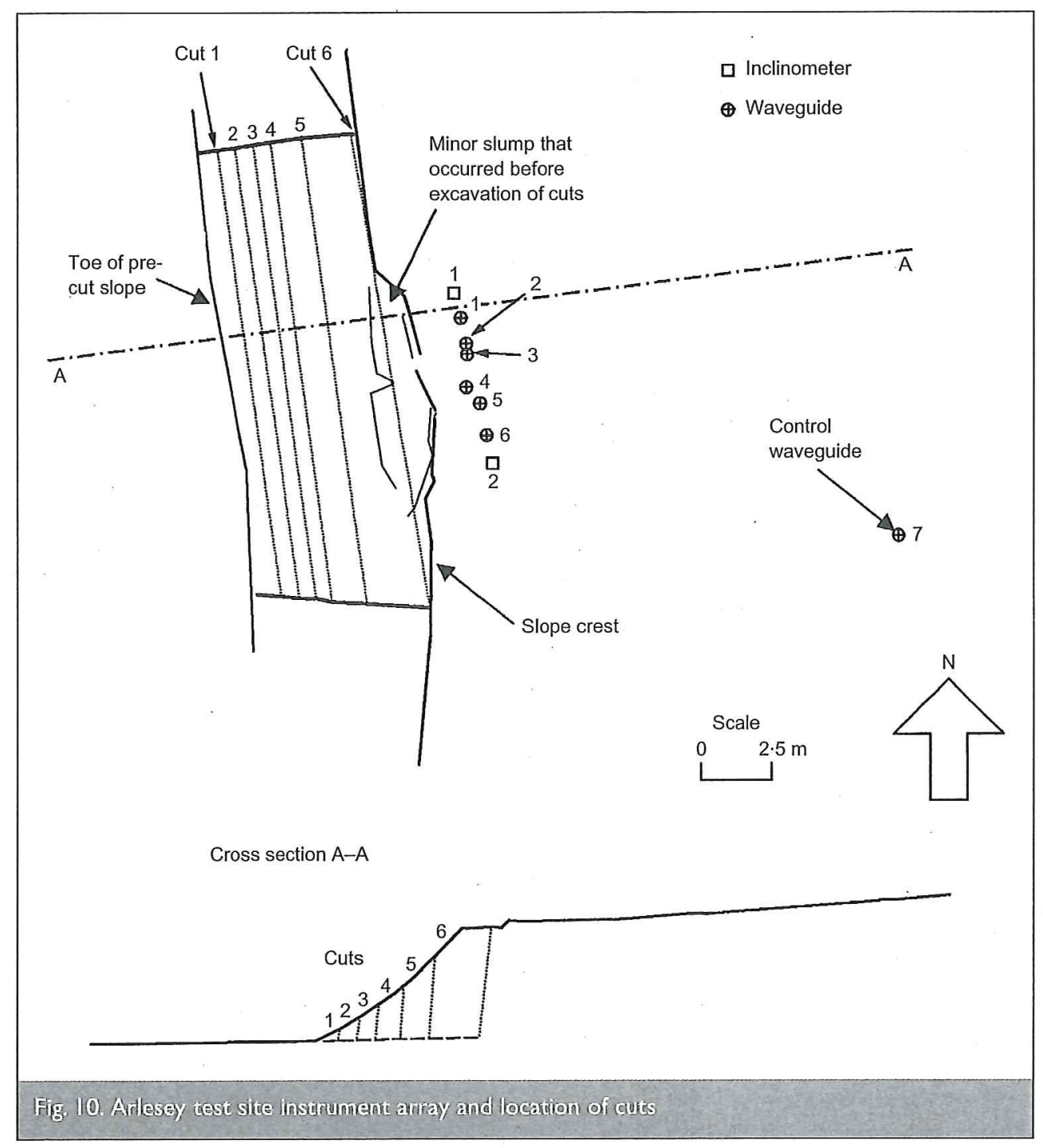




\begin{tabular}{|llcl|}
\hline Instrument type & Code & $\begin{array}{c}\text { Depth below ground } \\
\text { level: } \mathrm{m}\end{array}$ & Backfill \\
\hline Waveguide & WGI & $7 \cdot 1$ & Gravel \\
Waveguide & WG2 & $6 \cdot 6$ & Sand \\
Waveguide & WG3 & $7 \cdot 1$ & Grout \\
Waveguide & WG4 & $2 \cdot 7$ & Driven \\
Waveguide & WG5 & $2 \cdot 9$ & Sand \\
Waveguide & WG6 & $6 \cdot 7$ & Sand \\
Waveguide & WG7 & $2 \cdot 8$ & Sand \\
Inclinometer & II and WGi & $9 \cdot 0$ & Grout \\
Inclinometer & I2 & $9 \cdot 0$ & Grout \\
& & & \\
& & & \\
\hline
\end{tabular}

signal was corrected to remove background noise, and this was achieved by subtracting the value obtained from monitoring control waveguide WG12 on each visit to the site (WG 12 was $6 \mathrm{~m}$ long with sand backfill and was located behind the failure zone). Waveguides 1, 2 and 3 were $21 \mathrm{~m}$ long and arranged in a row parallel to, and approximately $4 \mathrm{~m}$ from, the cliff edge. There is a good
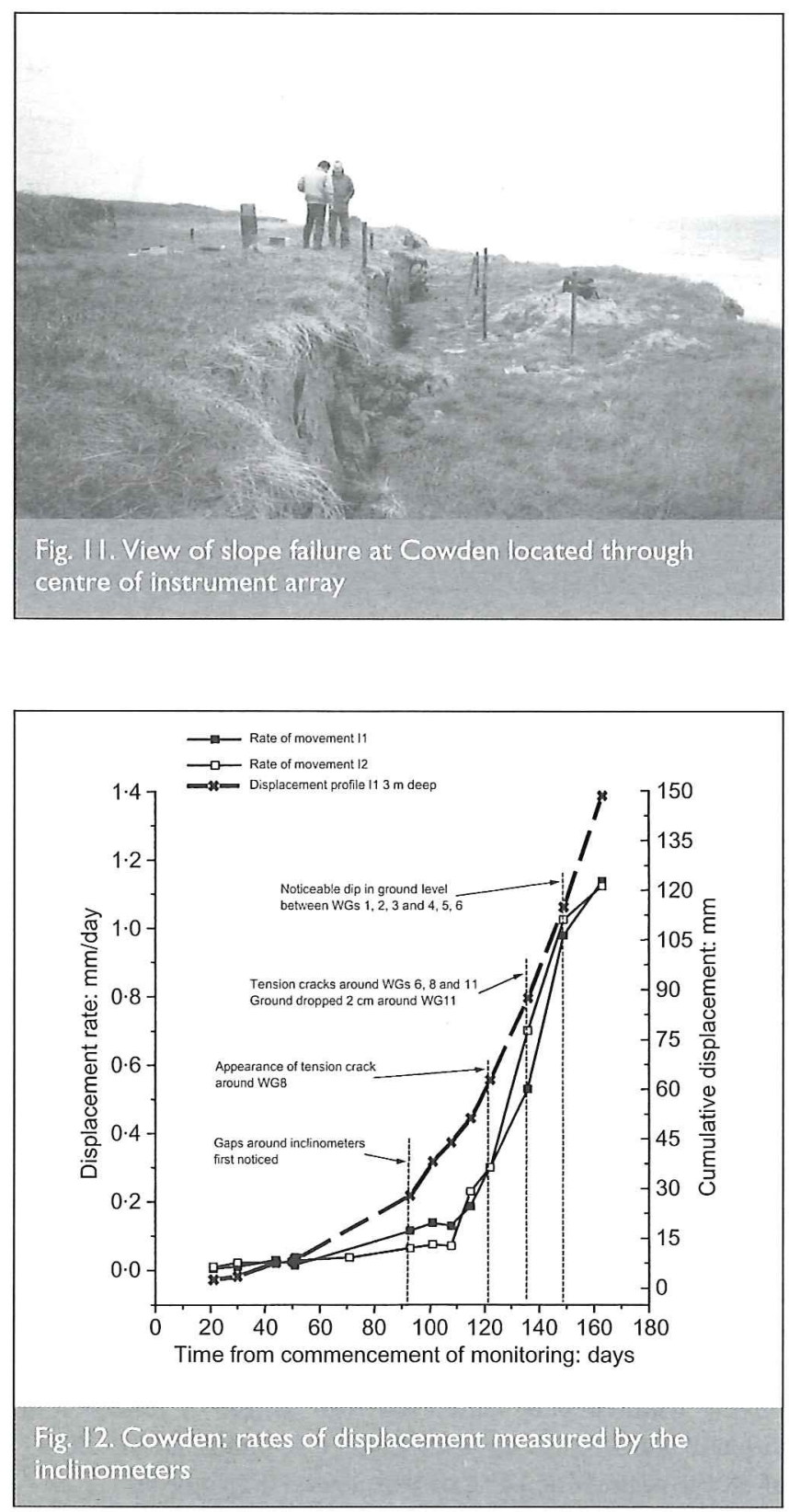

the significant increase after day 108. Fig. 13 shows the cumulative area under the AE signal recorded for waveguides 1, 2 and 3 (installed using sand, gravel and bentonite/cement grout respectively) over the test period. The area under the

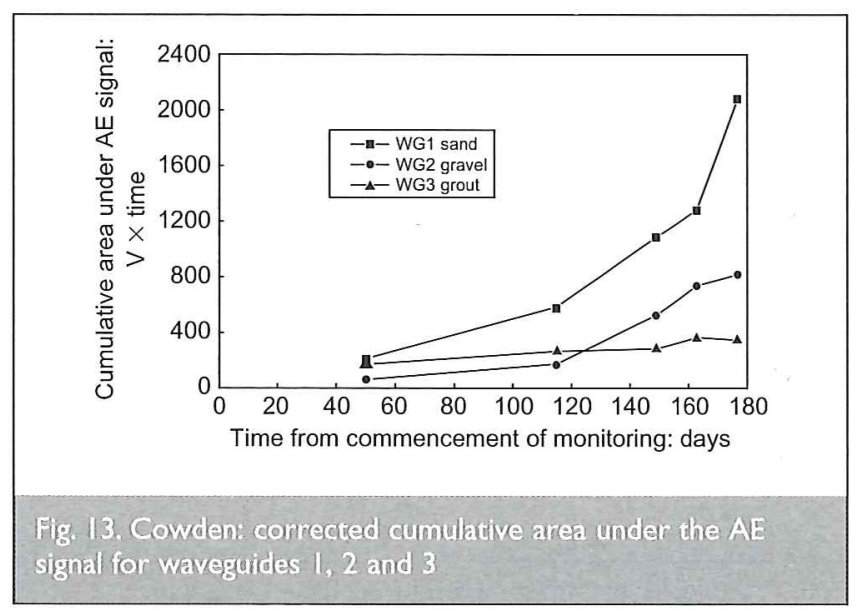

correlation between ground deformations and AE data, with a clear agreement between the AE trend with time and the rate of displacements. Typically, waveguide WG1 (sand) recorded the highest response, followed by WG2 (gravel) and WG3 (bentonite).

This good agreement supports the validity of the active waveguide model. The area under the acoustic emission signal provides an indication of the AE energy, and this would be expected to increase as the rate of displacement increases. Fig. 13 also demonstrates the different behaviour of the three backfill materials. The grout backfill (WG3) recorded the lowest level of $\mathrm{AE}$, the sand backfill (WG1) the highest level of AE, and the gravel backfill (WG2) recorded an intermediate level. These findings are consistent with the active waveguide model.

Inclinometer readings indicate the displacements that have occurred since the previous reading; however, the AE values are instantaneous results for a 3 min period on the day of monitoring. The fact that there is such close agreement is encouraging, although continuous monitoring is preferable if possible. The agreement suggests that acoustic emission is generated over extended periods of time in slopes subject to regular destabilisation events (marine erosion in this case). The sand backfill gave a better response than the gravel because it remains unstable for a longer period following a destabilisation event. This is consistent with results from the laboratory box tests. The Cowden field trial proved that acoustic emission 
waveforms could be recorded using portable instrumentation, and a relationship was established between $\mathrm{AE}$ from an active waveguide system and the rate of slope movements. However, as the slope started to deform before the $\mathrm{AE}$ monitoring system became fully operational, this field trial did not establish whether such a system could detect the onset of failure at an early stage. The Arlesey trial was designed to investigate acoustic emission monitoring of pre-failure behaviour.

\subsection{Arlesey results: relatively slow slope movements}

Figure 14 shows the maximum cumulative displacements for inclinometer casings I1 and I2 (recorded at depths of 1.5 and $0 \mathrm{~m}$ respectively) during the period of excavation at Arlesey. The data demonstrate that there were no detectable ground movements as a result of cuts 1,2, 3 or 4 . Significant deformations occurred after cut 5 , and the rate accelerated after cut 6 , shortly after which monitoring was discontinued. The acoustic emission results from waveguides WG1, WG2 and WG3, incorporating gravel, sand and grout backfill respectively, are shown in Fig. 15. Each plotted point has been obtained by calculating the mean voltage of all data points recorded during each individual monitoring period (that is, the mean of approximately 900000 data points). The significant data points are those for the gravel (WG1) and sand (WG2) backfill waveguides obtained after cuts 4 and 5 . These show levels of acoustic emission significantly higher than all 10 precut readings, which exhibited little variation. These acoustic emission data indicate that ground deformations occurred in

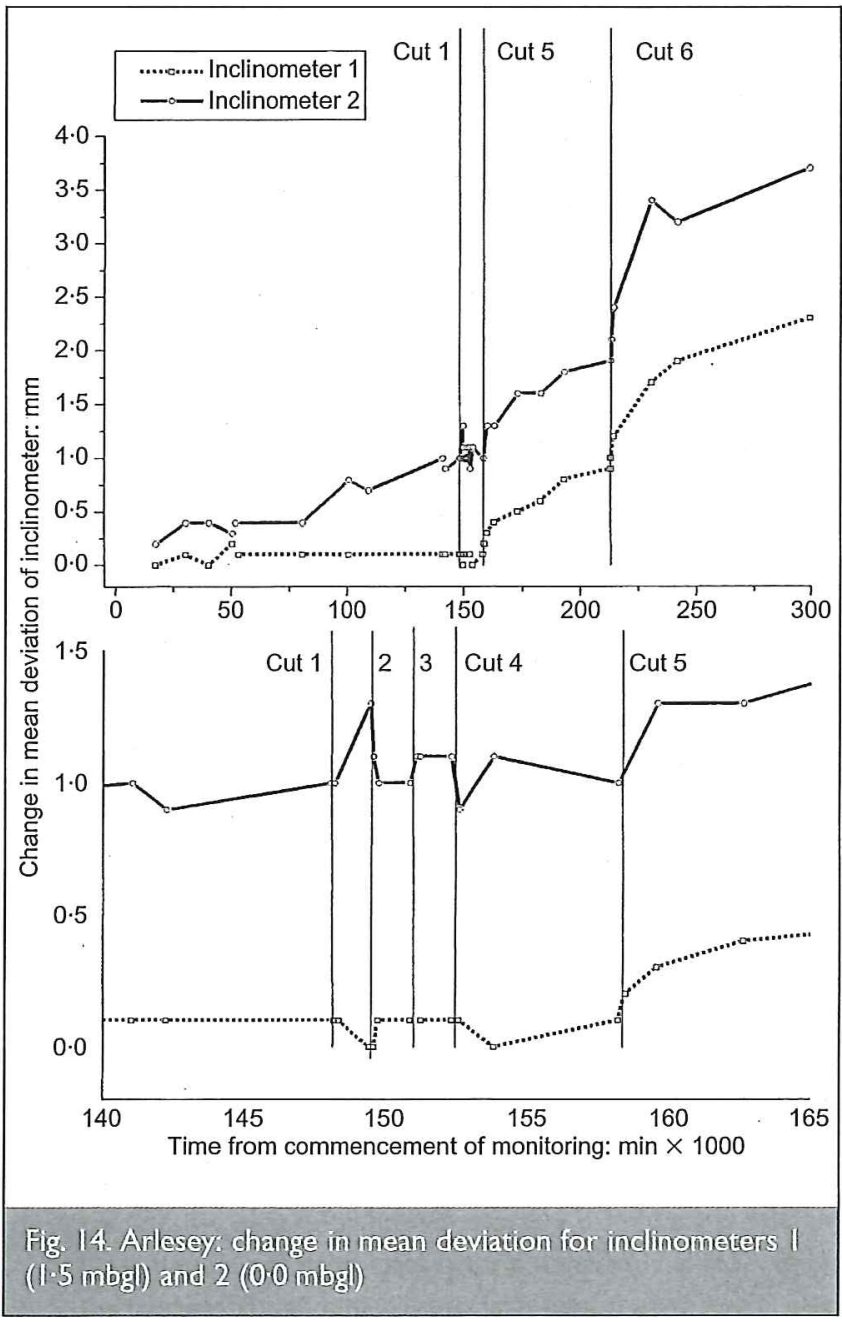

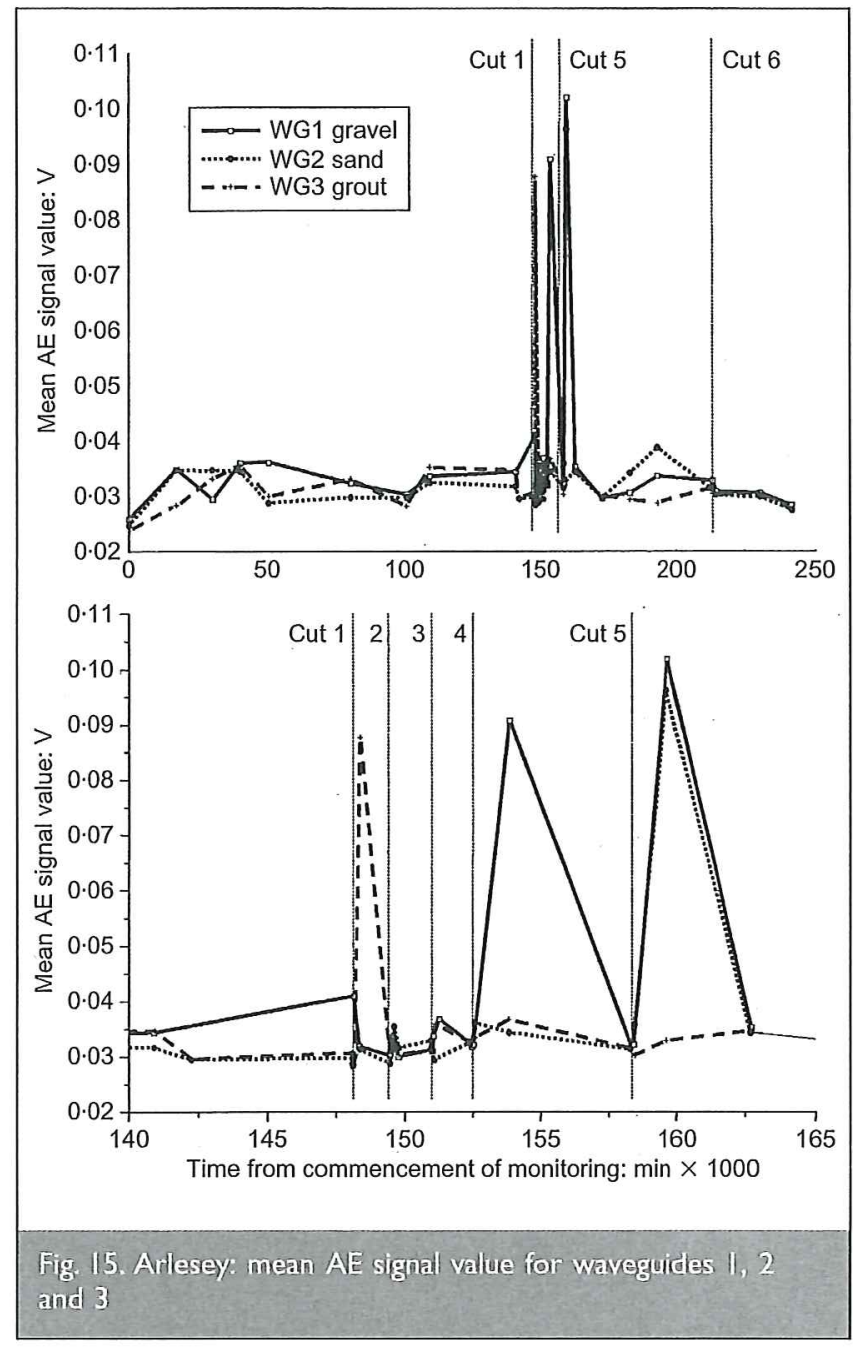

response to cuts 4 and 5. A notable point is that the $\mathrm{AE}$ indicated deformations after cut 4 at a time when the inclinometer was showing no change (Fig. 14). The grout waveguide (WG3) recorded a response to cut 1, but in general did not record acoustic emission. The response to cut 1 is discussed below. The driven waveguide (WG4) also did not record any detectable $\mathrm{AE}$ during destabilisation of the slope. The sporadic nature of ground deformations in response to stress relief resulting from excavation of the slope toe, in conjunction with the limited period of time during which $\mathrm{AE}$ was monitored, makes it difficult to establish a more complete picture of acoustic emission behaviour. This could only have been achieved by carrying out continuous monitoring during the excavation period.

Data were acquired by monitoring each waveguide for a fixed period of time. The intention was to capture as much data over as a long a period as possible to obtain a representative sample. Having acquired 'bulk' data it was then possible to process it in different ways. It was discovered that calculating mean values of all the acquired (bulk) data was a good indicator of sustained activity, such as that detected at Cowden and in the latter parts of the Arlesey test. Calculating the mean value of only post-threshold data was a good indicator of short-term activity, such as that detected in the initial excavations of the Arlesey tests. Calculation of the standard deviation (a measure of the spread of the data) provided additional information on 
periods of activity as shown in Fig. 16, where the AE response of a sand-backfilled waveguide (WG2 at Arlesey) obtained by calculating the mean voltage of the bulk data is compared with the standard deviation of data above the threshold voltage. The latter approach appears to indicate a prolonged period of activity, particularly in the case of cuts 4 and 5 . The acoustic emission recorded by WG2 following cut 1 is believed to be due to settlement of the sand backfill around the waveguide caused by low-frequency ground vibrations generated by the excavator working at the bottom of the slope. A similar response was given by a number of the waveguides following the first few cuts (for example the grout waveguide WG3, Fig. 15). This demonstrates that care must be taken during waveguide installation to form a dense annulus of backfill that cannot be disturbed by construction plant activity. However, the fact that a waveguide system can instantly generate a high magnitude of $\mathrm{AE}$ as a result of an input of energy is in itself a reassuring result. Kavanagh ${ }^{19}$ gives full results from all the waveguides and a detailed comparison of observed behaviour.

\subsection{Discussion of field trial results}

At both sites, recorded acoustic emission was controlled by the type of material used to backfill the annulus around the steel tubing. Coarse-grained soil based waveguides were found to produce the highest levels of AE, whereas the grout-backfilled instruments and the driven waveguide at Arlesey gave very

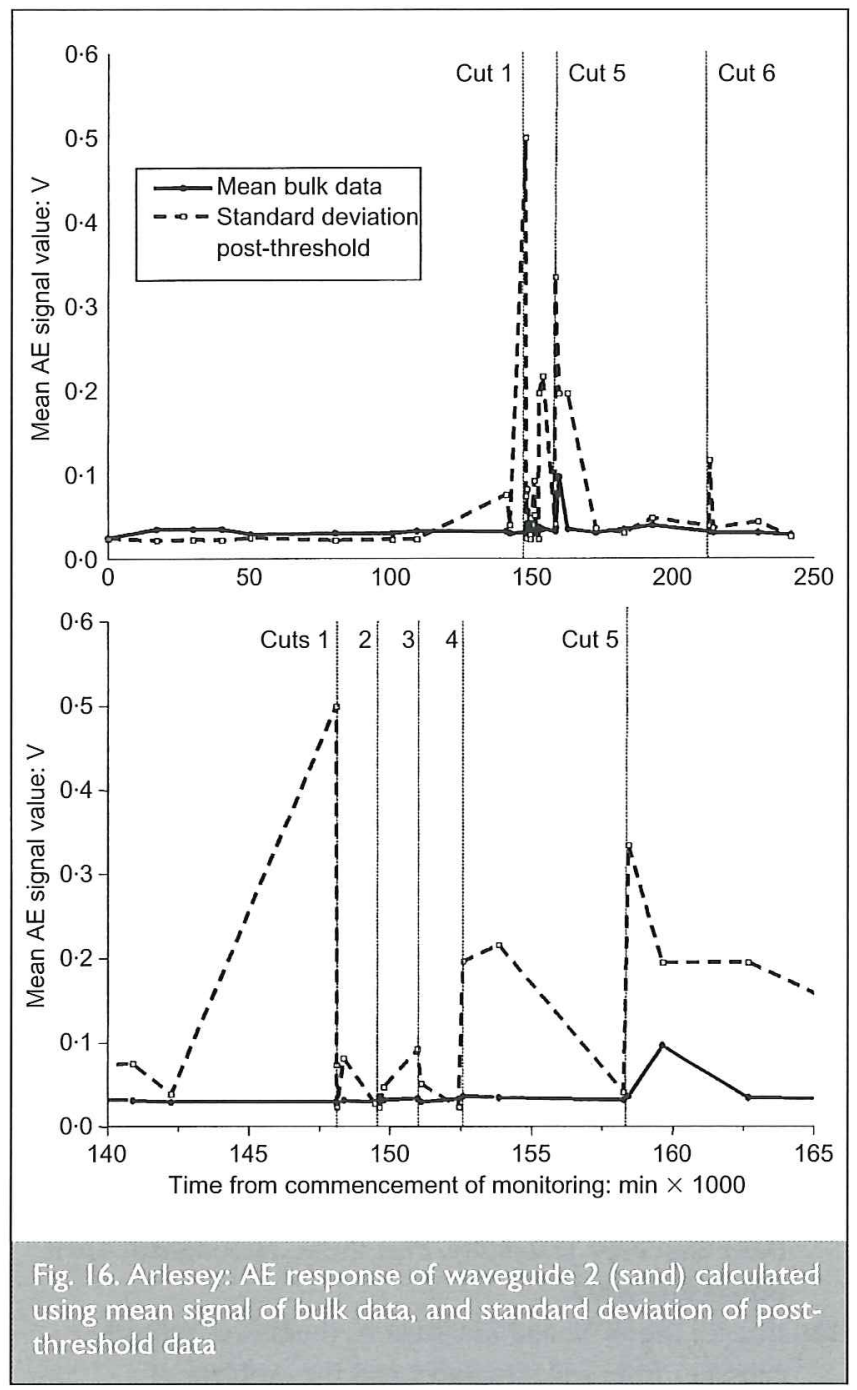

low values. These results confirm that the active waveguide model is the most appropriate for explaining the origin of the detected acoustic emission: that is, the AE is produced by deformation of the backfill to the steel tube in response to deformation of the host soil surround. It is considered that this approach is the most promising for future development of $\mathrm{AE}$ monitoring systems. An alternative approach was reported by Rouse et al., ${ }^{12}$ who described field trials where a passive waveguide system was used in conjunction with monitoring of lower frequencies (in the order of $6 \mathrm{kHz}$ ) to capture host-soilgenerated $\mathrm{AE}$ from an unstable slope. Although events were detected, there were concerns regarding the requirement for, and difficulty of, removing all sources of extraneous acoustic background noise. This is of particular importance if the technique is to be used for remote continuous monitoring.

Two main applications of slope stability monitoring are:

(a) as a means of routinely measuring the change in relative instability of a slope

(b) to generate an immediate alarm in response to a severe decrease in stability.

The Cowden study showed the potential use for case $(a)$, where signal level (indicated by cumulative area under the AE signal) demonstrated a generally rising trend during the onset of slope failure. This trend is comparable to that recorded by the inclinometers (Fig. 12). This behaviour was also seen in the period between cuts 4, 5 and 6 at Arlesey, where steady deterioration in slope stability was identified by standard deviation of the post-threshold AE data (Fig. 16). Even though $\mathrm{AE}$ monitoring was carried out for limited periods of time at the two sites, these studies confirm the validity of the active waveguide mode of behaviour.

The Arlesey study demonstrated that AE monitoring is capable of delivering an immediate response to a change in slope stability. The gravel backfill system produced a clear indication, using the mean signal level of the bulk data (Fig. 15), that slope deformations occurred in response to cut 4. Assessment of acoustic emission data through calculation of the mean signal level of the bulk data can be insensitive to short periods of $\mathrm{AE}$ activity during monitoring, and hence to small changes in stability of a slope. However, this also means that it is insensitive to sporadic spurious sources of AE, such as the construction-plant-generated signals recorded by the sand waveguide WG2 at Arlesey following cut 1 (Fig. 15).

Significant levels of acoustic emission (for example recorded using the gravel waveguide WG1 following cuts 4 and 5, Fig. 15) unequivocally indicate periods of deformation. In contrast, analysis using post-threshold data is sensitive to short periods of acoustic emission activity. Although this is of benefit when trying to identify pre-failure deformations, there is also the possibility of detecting acoustic emission generated by other sources, such as the construction-plant-generated signals recorded by the sand waveguide WG2 following cut 1 (Fig. 16). A potentially useful approach is to combine the two methods of data analysis in order to establish criteria for developing trigger values. Comparison of mean bulk data values with standard deviation of post-threshold values allows a robust assessment of when significant acoustic emission, and hence ground deformations, are recorded. In the pre-failure period the 
two values are coincident; they then diverge during deformation of the slope, as shown in Fig. 16. The different acoustic emission response of sand and gravel backfills has important implications for the design of field waveguide systems, with the selection of backfill depending upon the expected mode, the rate of slope deformation, and the method of monitoring (that is, continuous or at intervals). Ongoing research is investigating relationships between mode, rate and magnitude of active waveguide deformation and acoustic emission response. Work is also in progress to develop automated processing techniques for locating the source of signals along the length of the waveguide. This body of research is required to develop acoustic emission monitoring into a practical and reliable technique for assessing slope instability.

\section{CONCLUSIONS}

An investigation has been carried out into the use of acoustic emission monitoring for assessing unstable soil slopes. The results obtained from the field trials indicate that acoustic emission could be used for routine monitoring of slope instability as a complement to existing deformationmonitoring methods. The technique has a particular application as an early warning system. The most promising area of research relates to the use of active waveguide systems in conjunction with assessment of signal characteristics. Tube waveguides have been used because Lamb waveforms are transmitted with low attenuation.

Field-generated acoustic emission detected using $30 \mathrm{kHz}$ resonant frequency transducers is generated primarily by the active waveguide system and not by the host soil. Sand and gravel backfills produced detectable acoustic emission in response to periods of slope instability. Sand backfills remain emissive for a greater period of time, but gravel backfills can generate acoustic emission responses of greater magnitude in response to deformations. A relationship has been found between the rate of ground deformations and detected acoustic emission. A combination of signal processing methods (for example mean signal values for bulk and post-threshold) can be used to detect the onset of slope deformations. Although active waveguides do not directly monitor the stress state of the host material, they do enable the early detection of ground deformations and assessment of changes in the relative stability of a slope. Recent increases in processing power and portability of instrumentation provide the possibility of developing specialist equipment for field monitoring that can operate continuously.

\section{ACKNOWLEDGEMENTS}

A grant from the UK Engineering and Physical Sciences Research Council (GR/H80156) made the field work possible. Mr Kavanagh was supported financially by The Nottingham Trent University and EPSRC. Thanks are due to the Building Research Establishment and the staff at RAF Cowden for allowing access to the test site, and Kingston University for the loan of the drill rig used to install the instrumentation at Cowden. Also, thanks are due to Butterly Brick for allowing the use of the Arlesey site, John Cole for his help during the field work, and Matthew Spriggs for his comments on the paper.

\section{REFERENCES}

1. DunNicLIFF J. Geotechnical Instrumentation for Monitoring Field Performance. Wiley, New York, 1988, p. 577.

2. SCHUSTER R. L. and KRIZEK R. J. (eds) Landslides Analysis and Control. National Academy of Science, Washington, DC, 1978, Transportation Research Board Special Report 176.

3. MCCAULEY M. L. Monitoring slope stability with acoustic emission. Proceedings of the 1st Conference on Acoustic Emission/Microseismic Activity in Geologic Structures and Materials, Pennsylvania State University, 1977, 257-269.

4. HARDY H. R. Jr Geotechnical field applications of AE/MS techniques at the Pennsylvania State University: a historical review. Journal of NDT \& E International, 1994, 27, No. 4, 191-200.

5. KOERNER R. M., MCCABE W. M. and LORD A. E. (1981) Acoustic emission behaviour and monitoring of soils. In Acoustic Emission in Geotechnical Practice, American Society for Testing and Materials, ASTM STP 750, pp. 93-141.

6. KOERner R. M., LORD A. E. and MCCABE W. M. The challenge of field monitoring of soil structures using $\mathrm{AE}$ methods. Proceedings of the 2 nd Conference on Acoustic Emission/Microseismic Activity in Geologic Structures and Materials, Pennsylvania State University, 1978, 275-290.

7. Chichibu A., NAKAMURA K. J. M. and KamatA M. Acoustic emission characteristics of unstable slopes. Journal of Acoustic Emission, 1989, 8, No. 4, 107-112.

8. NAKAJMMA I., Negishi M., UJHHRA M. and TANabe T. Application of the acoustic emission monitoring rod to landslide measurement. Proceedings of the 5th Conference on Acoustic Emission/Microseismic Activity in Geologic Structures and Materials, Pennsylvania State University, 1991, 505-520.

9. SHIOTANi T. and OHTsu M. Prediction of slope failure based on AE activity. In Acoustic Emission: Standards and Technology Update (VAHAviolos S. J. (ed.)). American Society for Testing and Materials, 1999, ASTM STP, Pennsylvania, 1353, pp. 156-172.

10. HARDY H. R. Jr Monitoring of rock and soil slopes and landslide areas using AE/MS techniques: a state-of-the art review: Proceedings of the International Conference on Monitoring, Surveillance and Predictive Maintenance of Plants and Structures, Italian Society for Nondestructive Testing, Sicily, 1989, p. 11-21.

11. Kотесна P. The Use of Acoustic Emission Phenomenon in Geotechnical Engineering. MSc thesis, Imperial College of Science and Technology, University of London, 1982.

12. Rouse C., StYles P. and WILSON S. A. Microseismic emissions from flowslide-type movements in South Wales. Engineering Geology, 1991, 31, 91-110.

13. DiXon N., KaVANagh J. and Hill R. Monitoring landslide activity and hazard by acoustic emission. Journal of the Geological Society of China, 1996, 39, No. 4, 437-464.

14. ALLEYNE D. N. and CRAWLEY P. Long range propagation of Lamb waves in chemical plant pipework. Materials Evaluation, 1997, 55, 504-508.

15. KOUSTENI A. Acoustic Emission Waveguide Systems for Detecting Slope Instability. $\mathrm{PhD}$ thesis, Nottingham Trent University, 2003.

16. HiLl R., DiXon N. and KoustenI A. Studies of acoustic emission from soil structures and the problem of 
calibration. Proceedings of the 15th International Acoustic Emission Symposium, Tokyo, 2000, 77-84.

17. Cooper M. R., Bromhead E. N., Petley D. J. and GRant D. I. Selbourne cutting stability experiment. Géotechnique, 1998, 48, No. 1, 83-101.

18. BUTCHER A. P. The observation and analysis of a failure in a cliff of glacial till at Cowden, Holderness. Proceedings of the International Conference on Slope Stability, Isle of Wight, 1991, pp. 271-276.

19. Kavanagh J. The Use of Acoustic Emission to Monitor the Deformation of a Soil Body. PhD thesis, The Nottingham Trent University, 1997.

Please email, fax or post your discussion contributions to the secretary by I October 2003: email: mary.henderson@ice.org.uk; fax: +44 (0)20 7799 1325; or post to Mary Henderson, Journals Department, Institution of Civil Engineers, I-7 Great George Street, London SWIP 3AA. 